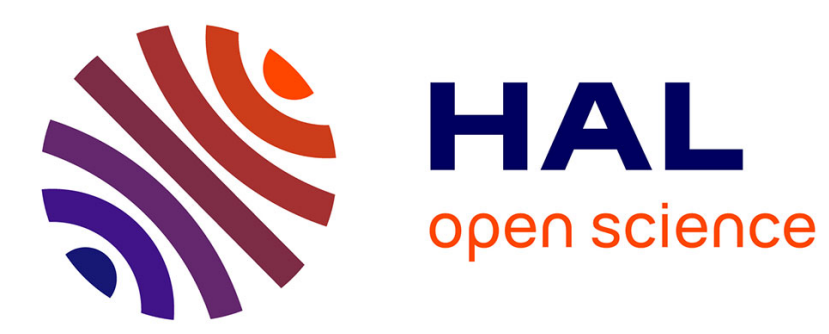

\title{
An improved approach for automatic process plan generation of complex borings
}

\author{
Alain Etienne, Jean-Yves Dantan, Ali Siadat, Patrick Martin
}

\section{To cite this version:}

Alain Etienne, Jean-Yves Dantan, Ali Siadat, Patrick Martin. An improved approach for automatic process plan generation of complex borings. Computers in Industry, 2006, 7 (57), pp.663-675. 10.1016/j.compind.2006.03.002 . hal-01022739

\section{HAL Id: hal-01022739 https://hal.science/hal-01022739}

Submitted on $10 \mathrm{Jul} 2014$

HAL is a multi-disciplinary open access archive for the deposit and dissemination of scientific research documents, whether they are published or not. The documents may come from teaching and research institutions in France or abroad, or from public or private research centers.
L'archive ouverte pluridisciplinaire HAL, est destinée au dépôt et à la diffusion de documents scientifiques de niveau recherche, publiés ou non, émanant des établissements d'enseignement et de recherche français ou étrangers, des laboratoires publics ou privés. 


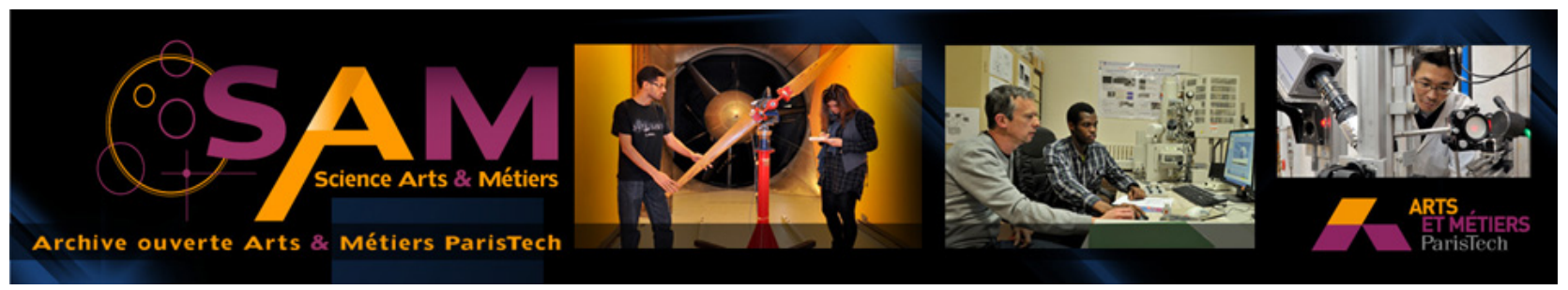

Science Arts \& Métiers (SAM)

is an open access repository that collects the work of Arts et Métiers ParisTech researchers and makes it freely available over the web where possible.

This is an author-deposited version published in: http://sam.ensam.eu

Handle ID: .http://hdl.handle.net/10985/8342

\section{To cite this version :}

Alain ETIENNE, Jean-Yves DANTAN, Ali SIADAT, Patrick MARTIN - An improved approach for automatic process plan generation of complex borings - Computers and Industry - Vol. $7, n^{\circ} 57$, p.663-675- 2006 


\title{
An improved approach for automatic process plan generation of complex borings
}

\author{
Alain Etienne*, Jean-Yves Dantan, Ali Siadat, Patrick Martin \\ Laboratoire de Génie Industriel et de Production Mécanique, E.N.S.A.M. Metz, 4 rue A. Fresnel, 57070 METZ Cedex, \\ France
}

\begin{abstract}
The research concerns automated generation of process plans using knowledge formalization and capitalization. Tools allowing designers to deal with issues and specifications of the machining domain are taken into account. The main objective of the current work is to prevent designers from designing solutions that would be expensive and difficult to machine. Among all available solutions to achieve this goal, two are distinguished: the generative approach and the analogy approach. The generative approach is more adapted to generate the machining plans of parts composed of numerous boring operations in interaction. However, generative systems have two major problems: proposed solutions are often too numerous and are only geometrically but not technologically relevant. In order to overcome these drawbacks, two new concepts of feature and three control algorithms are developed. The paper presents the two new features: the Machining Enabled Geometrical Feature (MEGF) and the Machinable Features $(\mathrm{MbF})$. This development is the result of the separation of the geometrical and the technological data contained in one machining feature. The second objective of the paper is to improve the current Process Ascending Generation (PAG) system with control algorithms in order to limit the combinatorial explosion and disable the generation of unusable or not machinable solutions.
\end{abstract}

\section{Introduction}

The contractual link between the three major actors at the beginning of the product lifecycle, namely, the design department, the manufacturing department and the production management department, is performed by the process plan [13]. A similar observation can be applied to underline the importance of Computer Aided Process Planning (CAPP) devices which are located at the intersection of applicability of Computer Aided Design (CAD), Computer Aided Manufacture (CAM) and Enterprise Resources Planning (ERP) systems. The stake of the integration of CAPP systems in production environment is depicted in several papers $[4,5]$. Indeed, a relevant CAPP is a device which can hastily take the specifications of all partners into account while summarizing them in one document: the process plan.

The available tools dedicated to automatically generate process plans (for instance PART [6]) are still scarcely used in

\footnotetext{
* Corresponding author. Tel.: +33 3873 75441; fax: +33 387375470 .

E-mail address: alain.etienne@metz.ensam.fr (A. Etienne).
}

Europe. In continuous improvement, solutions proposed with CAD-CAM software can currently only automate association between geometrical features and their processes. This approach, which needs continuous and important capitalization of data, is only effective for stereotyped morphology parts (this is typical of the automotive industry). This work takes place in the framework of current studies relating to semi-automatic generation of process plans applied to machining axial features.

However, these tools are not adapted to the generation of machining plans of hydraulic and aeronautical parts whose morphology are more complex: these parts are made of a huge number of axial entities with many topological or tolerance interactions, and are not presenting privileged directions of accessibility [7]. The aim of this study is to setup the concepts and methods allowing the generation of machining process for these types of parts and to implement these solutions in a module that can be used by many CAD-CAM software packages.

Two approaches to generate process plans are currently used (Fig. 1). First, there is the variant approach based on alternative cases. All parts already designed and machined in the company are categorized according to their morphology and dimensions, 


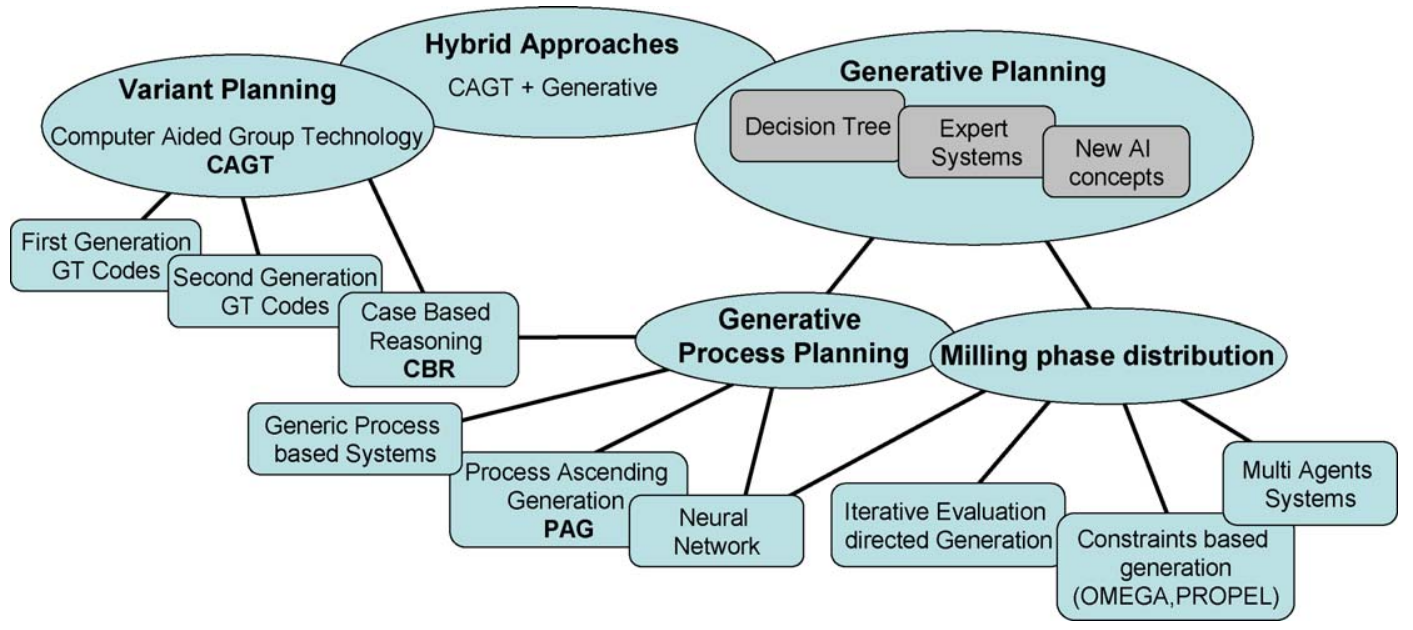

Fig. 1. Milling plans generation concepts [12].

process plans or other intrinsic characteristics considered relevant and discriminating. When a new part is designed, it is then possible to find all similar cases and thus to select the corresponding plan [8]. However, the use of such a method requires tremendous capitalization of the know-how of company's process planners (about 5-7 years of capitalization to be effective according to Ref. [9]). In addition, several other difficulties exist: the durability of plans and technical solutions produced, the lack of flexibility (it is impossible to adjust one routing if the part to be performed differs locally from the saved reference) and the subjectivity of the part coding. This approach, in spite of the sizable time needed to capitalize knowledge and know-how, is really effective in performing generic plans. Nevertheless, as explain in Section 3, this method seems unusable considering the specifics of our issue.

The second approach or generative approach does not consist in retrieving and modifying an existing process plan but rather consist in generating it when a new part is designed. Furthermore, this method does not capitalize the problem and its solutions (the machined artifact and its process plan) but rather capitalizes the method and operations needed to find a solution. Among the numerous solutions of this approach, one can mention: artificial intelligence software systems (for example: PART [6] or PROPEL [10]), generic process based on systems (one machining feature is associated with the entire process needed to machine it $[11,12])$, and solutions using decision tree method (ordered and hierarchical list of rules). The Process Ascending Generation (PAG [13]) is one concept which complies with the generative approach. Section 3 reveals why this solution is relevant for our problem.

The main objective of our work is to propose concepts and to develop relevant databases and algorithms for the generation of a dozen plans at most, considering the know-how and knowledge of the users, the capabilities of the available tools and machines. A prototype is proposed. A side problem is to control the combinatorial explosion due to complexity, the main issue of current generative CAPP systems. At this stage, we consider that the product, entirely composed of axial features, is only machined with a 3-5-axe milling machine, starting from a blank part. Axial features, which are the input of our system, are the output of the recognition activity. Several papers deals with methods employed to recognize forms and features [7,14].

This paper is divided in two major parts. The first part deals with the concept of features. Indeed all current generative process planning systems use features. After analyzing the concept of machining features and underlying their drawbacks, two new features are proposed. The second part of the paper more particularly concerns process planning. After drawing up a state of play of concepts and methods needed to develop this kind of system, issues are underlined. To overcome these deficiencies, several interesting improvements such as the development of the PACG and the use of tools charts are explained.

\section{Machining feature concept}

Current process planning systems, such as modern CADCAM software packages, deal with the use of features [15]. The current status of this concept is drawn in Refs. [16,17]. As a solution of the complexity of current part designs, features perform the broking up of these workpiece in smaller and easier to handle concepts [18]. Several definitions of these features are available: from those needed to factorize machined parts [19] to those used for analyzing welded parts [20]. This key concept is preferred to mathematical or geometrical part definition because it can be enriched by several knowledge layers. Indeed, each expert playing a part in the lifecycle of one product can associate the knowledge needed by his skill domain to features composing the designed product. Several examples are shown in Ref. [21]: manufacturing, geometrical and functional information are supported by features. However, this is not an exhaustive list since features can be enriched with cost, tolerance or tools data ...

Moreover, this view is compatible with the object-oriented paradigm [22]; one feature is equal to one class: both can be enriched with parameters and methods. It results from this modeling some interesting possibilities of association and description for our work. 


\subsection{Machining features}

When particularly applied to the machining domain, a feature is the combination of a geometrical definition (enriched with technical characteristics) and a semantic definition inspired by process planning engineers. According to the French community GAMA, a machining feature is a semantic set characterized by a collection of parameters used to describe an indecomposable object relative to one or more activities related on the design and the use of products and systems of production [23].

Considering the axial features [24,25], L. SABOURIN suggests a definition of several machining features: these entities, described with geometrical parameters, cannot nevertheless be dissociated from the technical functions they fulfil.

This is precisely the main deficiency of this concept: because one feature depicts both geometrical and technical information, if all features available cannot help to design a product, a new feature has to be created. While the separation of these two domains of knowledge is not carried out, creativity and innovation will be restrained.

\subsection{Two new feature concepts}

To overcome the deficiency due to using machining features only, and to help CAPP, two new concepts have been defined. These two concepts, the Machining Enabled Geometrical Feature (MEGF) and the Machinable Feature (MbF), result from the split of geometrical and technical data contained in machining features [26].

\subsubsection{The Machining Enabled Geometrical Feature $(M E G F)$}

Thanks to this separation between the geometrical definition of a machining feature and its commonly associated manufacturing process, it is possible to reduce the number of entities handled to an exhaustive list of five MEGF classes (they are illustrated in Fig. 2). Combined with a set of descriptive parameters (geometrical, topological interactions, material, tolerance ... as shown in Fig. 3), this allows a unique definition and semantic factoring of the part to analyze (one factoring example is shown in Fig. 2). At this stage, no information relating to the manufacturing domain (Tools, Operation or Sequences) is linked with these object classes. This splitting up was appraised and validated on a collection of aeronautical parts. In short, a MEGF is an elementary geometrical semantic set characterized by parameters used to describe an indecomposable geometrical object relative to the process planning activity.

With the aim of modeling the whole environment of these MEGF classes, a definite number of interaction cases between two MEGF have been identified and formalized. Indeed recognizing features without taking their surrounding into account is useless: the main manufacturing choices depend more on the interactions between entities than on the feature parameters themselves (for example, machining setups which depend a lot on topological interactions are determining economic inductors). Far from the formalization performed by REGLI and PRATT [27] who consider several types of interactions, we limit our study to topological and tolerance interactions. A discriminating mathematical definition for each case is available: only the directive vector, one point belonging to each entity, the diameter and the length of each one are sufficient to determine in which case of topological interaction two MEGF are. This topological interaction cases classification (Fig. 4) is inspired by the formalization made by L. SABOURIN [24]. At this stage, our formalization is able to take into account these MEGF classes, their surrounding (topological and tolerance inter-

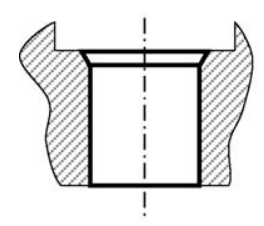

Through Bore

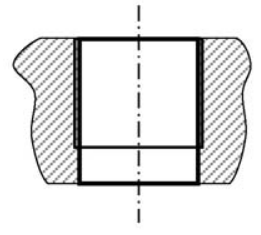

Taped Through Bore

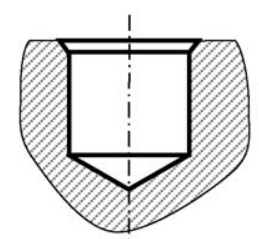

Non Through Bore

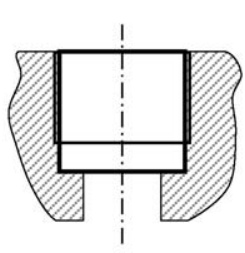

Non Through Taped Bore

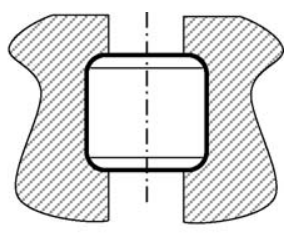

Chamber
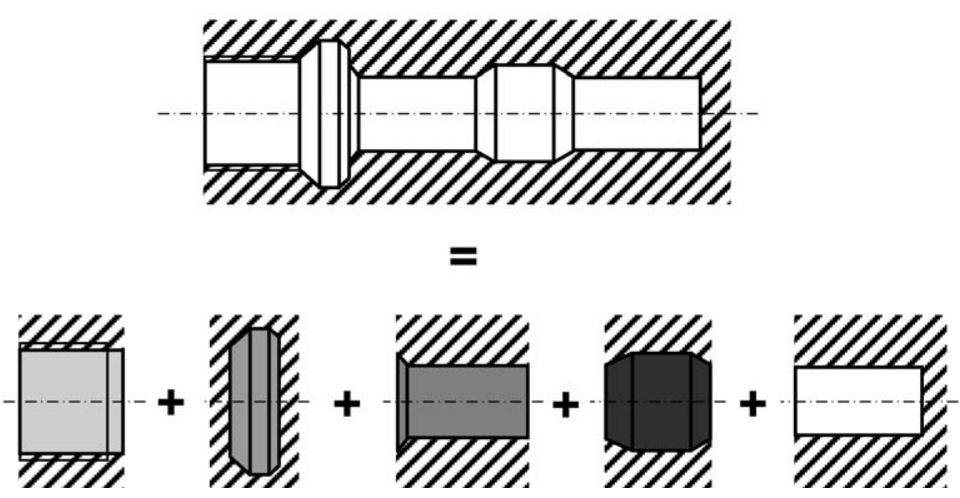

Fig. 2. The five MEGF classes and one boring factoring. 


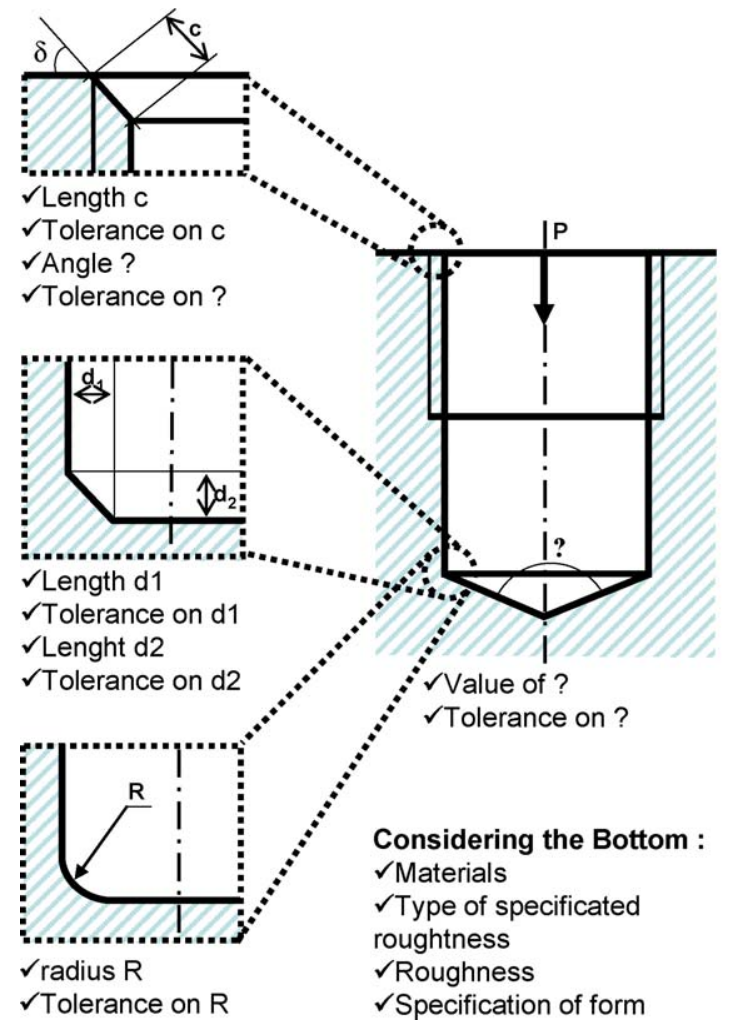

Generic parameters of the entity:

$\checkmark$ Coordonates of the origine point $(P)$ $\checkmark$ Coordonates of the directive vector $\checkmark$ Diameter of accessibility $\checkmark$ Distance from the surface $\checkmark$ Type of bottom

$\checkmark$ Type of entry chamfer

$\checkmark$ Diameter

$\checkmark$ Depth

$\checkmark$ Pitch

$\checkmark$ Diameter of the internal thread

$\checkmark$ Hand of helix

$\checkmark$ Number of fillet

$\checkmark$ Form of the fillet

$\checkmark$ Length of the thread

$\checkmark$ Materials

$\checkmark$ Type of spécificated roughness

$\checkmark$ Roughness of the roll

$\checkmark$ Tolerance on the diameter

$\checkmark$ Tolerance on the depth

$\checkmark$ Tolerance on the thread's diameter

$\checkmark$ Tolerance on the thread's length

$\checkmark$ Specification of location

Fig. 3. The MEGF "non-through tapped bore" and its parameters.

actions between two features, mounting and machining settings).

To take into consideration normalized features (as for instance the spark plug borings in a motor whose the geometry is defined by a standard), we add to the model the concept of composed machining enabled geometrical feature (CMEGF). This feature, which is still composed of MEGF, inherits the behaviour and parameters of all its components. As a consequence, the use of these features complies with the former machining features modelling needed by standards.

\subsubsection{The 'machinable' feature}

The machinable feature, the second concept, supports the manufacturing knowledge. In fact, one machinable feature characterizes the possibility of linking at least one Tool/ (Operation - Sequence) couple and a geometrical description from a (C)MEGF. In short:

One Machinable Feature

$$
=\text { One }(\mathrm{C}) \mathrm{MEGF}+\text { One Saved Op/Sequence }
$$

All these relevant links are stored in the cutting tools chart [13] (described in Section 3.2.4), a kind of table where the knowledge and know-how of the user is stored. At this stage, all associations are generated including non machinable and useless solutions! The next step is to select only adapted machining setups considering the means and capabilities of the user company.

Precisely, a machining feature in our modeling approach is instantiated by this selection activity: a machinable feature previously generated is analyzed considering mainly the context and know-how of the planners. If this feature succeeds, it will be transformed as a machining feature, a combination of geometrical descriptions and manufacturing parameters (operations or sequences + tools family). In short:

\section{One Machining Feature}

$=$ One Machinable Feature validated and selected

It is necessary to precise that, in this modeling approach, machinable and machining features are not handled by the process planner. In fact, these concepts materialize relevant links between geometrical entities (MEGF and/or CMEGF) and manufacturing parameters (machines, setup, tools, operations/ sequences, settings ...). This modeling method is illustrated with a UML model in Fig. 5. In brief, the only feature concept really handled by our algorithm (described in the further paragraph) is the geometrical feature (MEGF).

As a conclusion, using these three concepts associated with adequate algorithms minimizes the number of handled objects: the system is more flexible and robust. It is more flexible because users can easily add new CMEGF (a combination of basic MEGF), taking the know-how and machining abilities of the planner into account. It is more robust because the MEGFs, which are completely defined, are enough discriminating for the factorizing of the part geometry: no upgrade is needed. The next paragraph deals with the definitions and descriptions of these algorithms which support the three entities and overcome usual deficiencies of current process planning systems. 


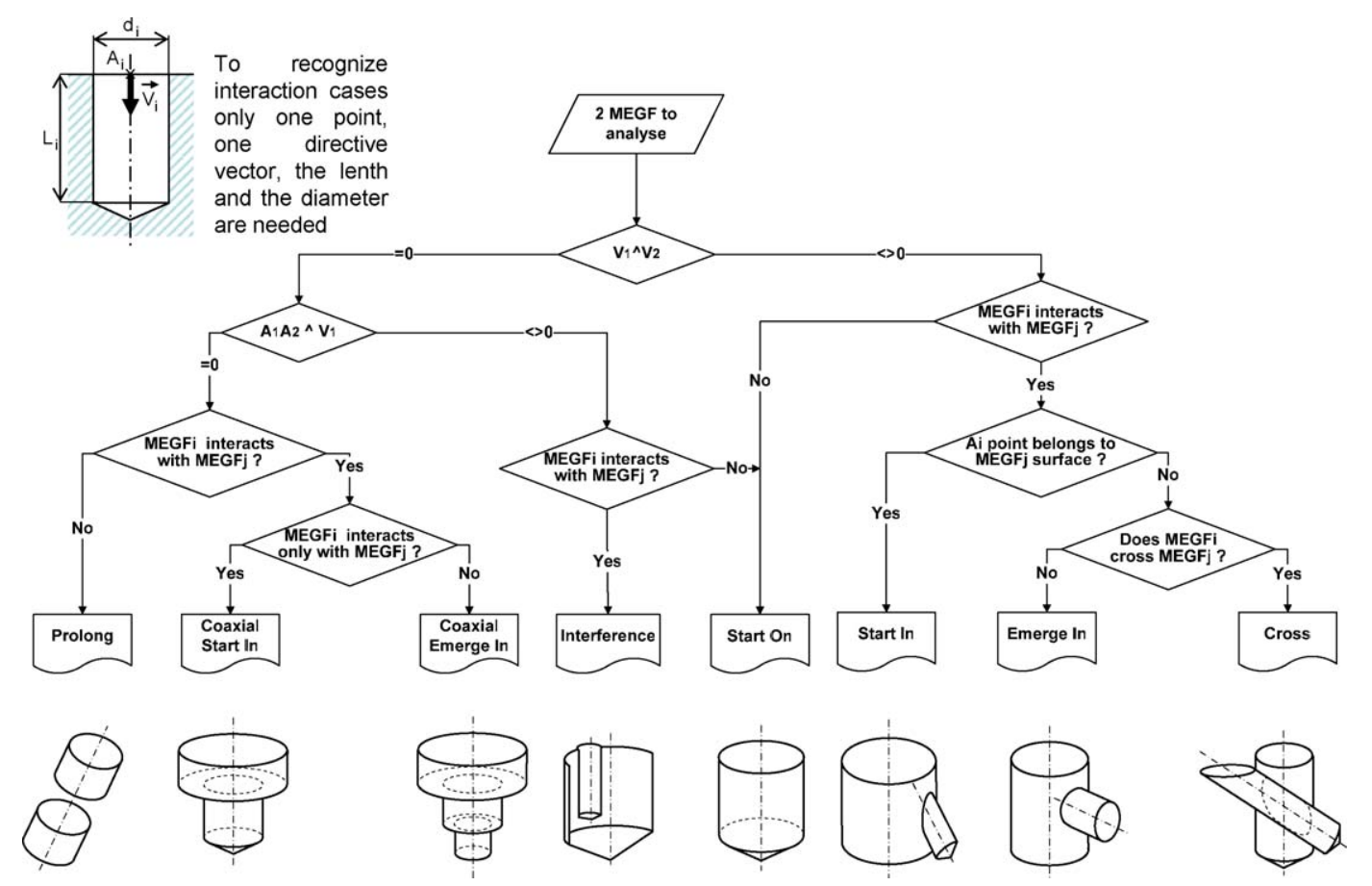

Fig. 4. Decision tree of interaction cases between two MEGF.

\section{Process planning}

Process planning systems are mainly designed to cater for the generation of the machining plan(s) of a workpiece to get time reduction and products that are cheaper to produce. In addition, using these CAPP systems during the design of a new product can both improve manufacturability and assessment of the manufacturing costs.

Most former process planning generation approaches (summarized in Fig. 1) are based on two ways of thinking by the process planning expert: reasoning by analogy and purely generative reasoning $[1,28,29]$.

As indicated in Section 1, the variant approach requires knowledge capitalization about all products already designed in the company: products have been coded according to relevant and discriminating parameters such as their morphology, the plan used to machine the part, or others intrinsic characteristics. The generation of a new process plan consists in finding all similar cases and thus to select the corresponding plan $[8,30,31]$. However, this method is not free from deficiencies: e.g. the durability of plans, the age of technical solutions used or the lack of flexibility (it is impossible to adjust a plan if the product to be manufactured differs locally from the saved reference). As regards the specificity of our problem (unit production of workpieces mostly made of axial features with numerous interactions), this approach seems unsuitable.

The generative approach produces the process plan when a new product is designed. This method does not capitalize on the

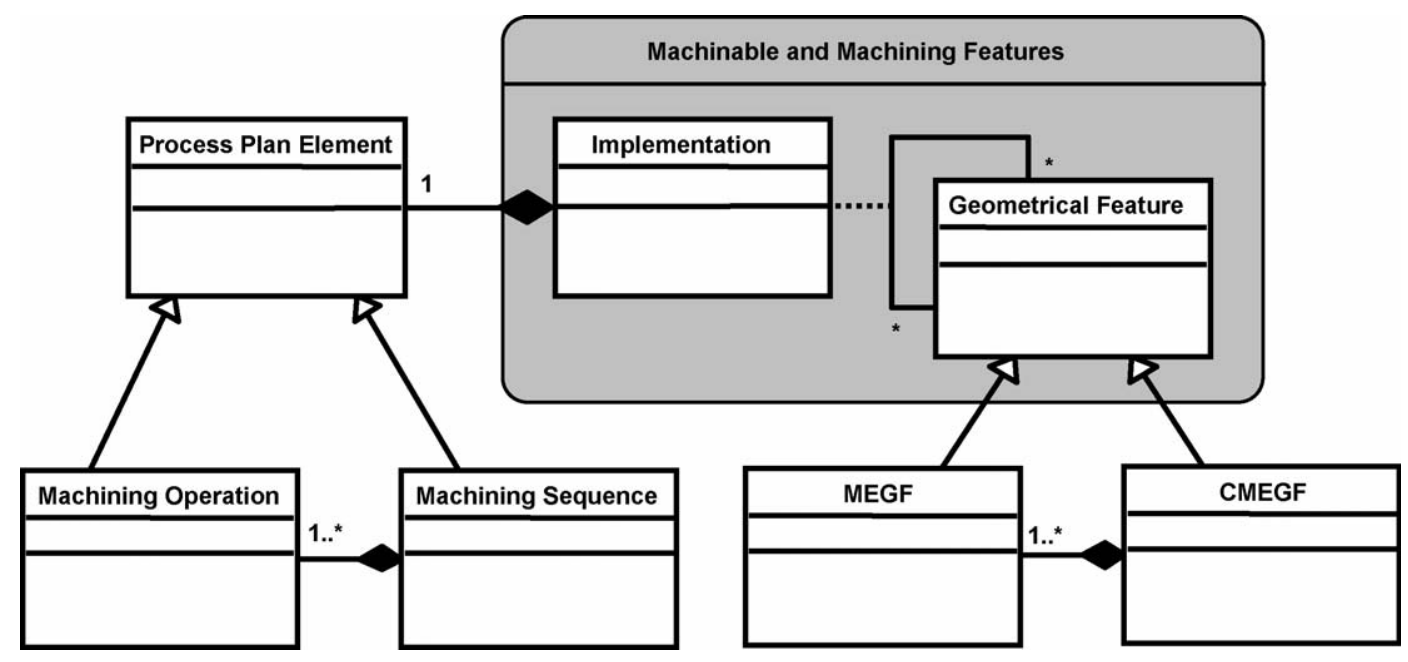

Fig. 5. UML model of handled feature. 


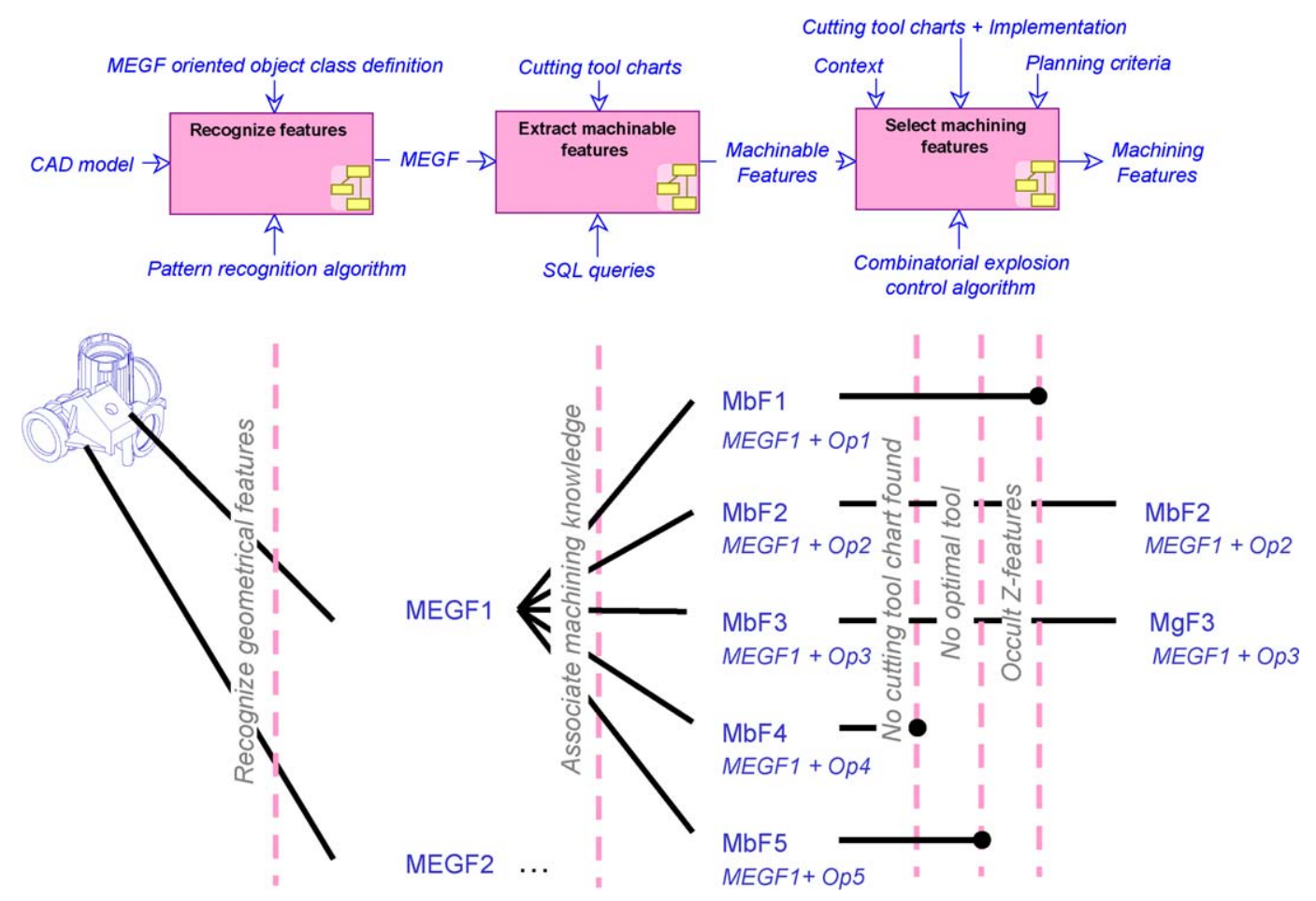

Fig. 6. Life cycle of the three features (MEGF, Machinable and Machining features).

problem and its solutions (the workpiece to be machined and its process plan) but on the applied reasoning. Process generation can be carried out with several tools: generation based on artificial intelligence (neural networks [32], expert systems [33], Constraints Programming devices such as PROPEL [10] or Cooperative Agents systems [34] are currently in development), generation of generic processes (one machining feature is associated with an entire process needed to machine it, ignoring its context and interactions). Then to construct the plan of a part, the selected processes are ordered [11,12]).

Regarding the framework of this study - an artifact made of several borings in interaction, which differs locally from previously stored plans - it seems difficult to have to use the variant method. Due to this drawback, the study has been restricted to the generative approach. Furthermore, after analyzing the needs of the solution it seems that using Artificial Intelligence techniques was not really necessary. Consequently, our framework is restrained to the use of a decision tree and the Process Ascending Generation concept [13]. This method is detailed in the next section.

\subsection{The Process Ascending Generation}

Among the systems based on the generative approach, the Process Ascending Generation holds our attention. This concept, which has been defined by VILLENEUVE [13], describes the succession of the process states of a workpiece from its finished state to the initial state. According to the PAG construction axioms, any intermediate state between the initial and the final state is a machining feature. Moreover, a state results from the application of a sequence: as a consequence, the parameters of the feature depend on the parameters of the change sequence and of the previous state of the feature. This PAG is illustrated in Fig. 6, for a given vertex $N_{1}$, the whole sequence performing this state is sought. When a relevant Sequence $S_{\left(N_{1}-N_{3}\right)}$ is found, the former possible state $N_{3}$ is generated with the combination of parameters from the $N_{1}$ feature and the $S_{\left(N_{1}-N_{3}\right)}$ characteristics.

Thus, a machining plan of a workpiece results from the concatenation of sequences met during the follow-up of one branch of the PAG tree (for instance: $N_{5}, N_{3}, N_{4}, N_{1}$ ). This method, which meets the requirements expressed in the introduction, is not free from some drawbacks.

First, the number of branches generated by this method is uncontrolled: due to combinatorial explosion, the number of intermediate features and relations between them can quickly reach infinity. This situation is a consequence of the method followed by the PAG: it tries to find simultaneously the previous state of each feature composing the analyzed vertex. Consequently, from the vertex $N_{1}$ too many previous vertexes and sequences are instantiated.

Furthermore, for a given vertex, it is unsure that the further states in the tree will be viable and will not lead to a sterile branch (for instance, the state $N_{2}$ cannot have any more antecedent: the Sequence $S_{\left(N_{1}-N_{3}\right)}$ and the State $N_{2}$ are called "dead branch" or "sterile branch").

As a conclusion, considering the possibilities and drawbacks raised by both approaches applied to our requirements, it could be interesting to combine the variant and generative methods. This approach associated with an improved version of the PAG concept (since designed with the aim of reducing useless states and "sterile branches") would be perfectly appropriate for the requirements of our process generation algorithm. 


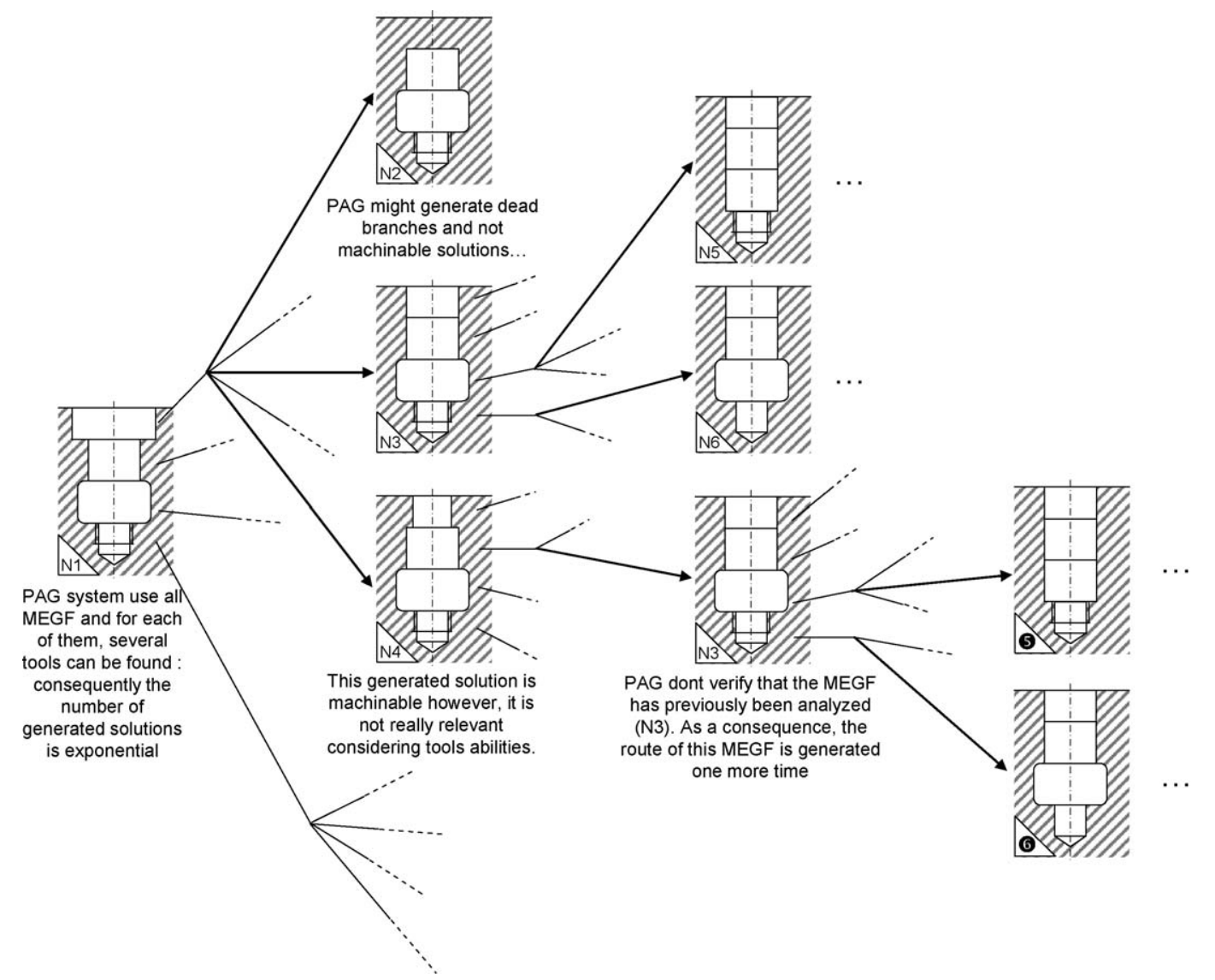

Fig. 7. Example of one intermediate states tree [12] of the PAG.

\subsection{The Process Ascending Controlled Generation (PACG)}

Considering that the main issues are the combinatorial explosion and the generation of useless branches, the goal of this section is to develop methods and a software program which overcome these problems. The result is named Process Ascending Controlled Generation (PACG).

This section consists of six parts; each describing a module of our PACG algorithm and explaining its aim, drawbacks and advantages. This factoring leads the activity model (Fig. 7), which illustrates the PACG tasks succession. The first subsection underlines the impact of using new features (Machinable Features and MEGF) on the process plan generation. The next sub-section deals with the relevance of using the sequence concept to realize the mix of both the generative and variant approach in the PACG system. The third sub-section describes the process control criteria which perform the selection of the best solutions considering technology habits and know-how of the company. This knowledge must be formalized and capitalized. This activity and its procedures, realized with the cutting tool charts are explained in Section 4. Current process generation solutions do not take care of the context of the features analyzed. The fifth sub-section describes the relevance of taking the context of features into account, the method designed and its realization in an algorithm. The last module explains the selection of cutting tools and the relevance of choosing it earlier.

\subsubsection{The impact of using MEGF and Machinable Feature}

Using the three entity concepts described in Section 2 is the first means to limit and control the propagation of useless branches. Indeed, as opposed to current methods, all machining entities are not instantiated but, through the generation of process plans, these features will follow a well defined lifecycle (illustrated in Fig. 8). First, the artefact to analyze is factorized with combination of the five MEGF classes. After analyzing the characteristics of these newly instantiated objects and fields of validity of all cutting tools charts available, these features are combined with manufacturing parameters. These new entities become machinable features. It means that, out of context, those features could be machined as regarding the manufacturing possibilities and the know-how of the user corporation. Finally, after taking interactions with surrounding features, the machining fixture and the impact of drilling the machinable feature into account, the algorithm selects only valid entities. These relevant machinable features become machining features and a new vertex is generated in the PACG tree.

Furthermore, using features and the object-oriented paradigm reduce widely the number of handled objects by avoiding object duplication. When several branches of the machining plan have a shared vertex, the algorithm will not generate twice the same features and all associated machining plans. In fact, if a branch needs an existing vertex, it will point at it with a Tool/ Operation link (an example is illustrated by annotation 4th in Fig. 9). 

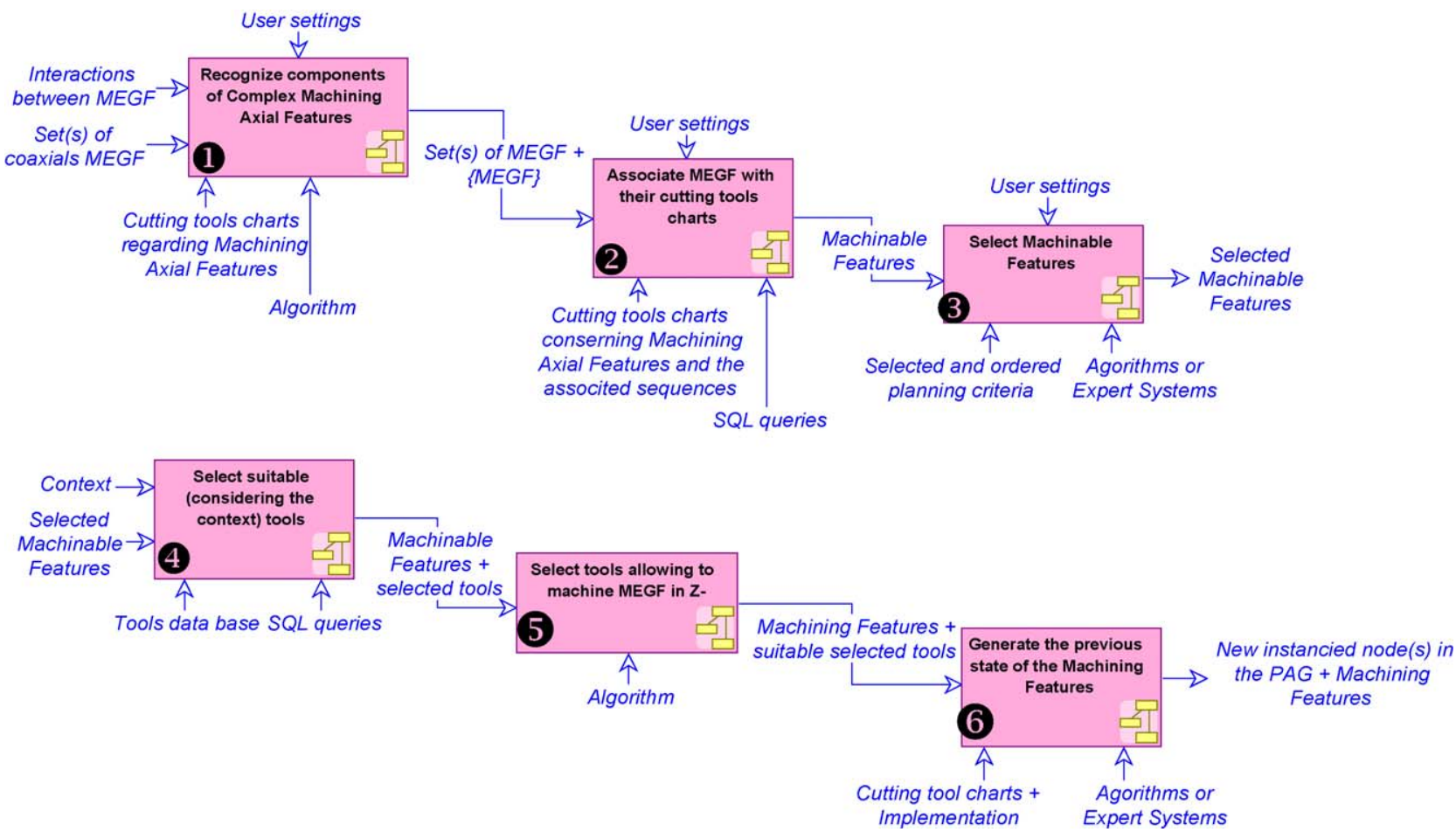

Fig. 8. Activity model of the PACG algorithm.

In short, using these three features instead of only one and using to object-oriented programming take part in the development of a method minimizing the effects of the inherent defects of current CAPP systems.

\subsubsection{The interest of Sequences}

As shown in Section 3, it was decided to develop a system from the PAG concept, a generative approach based system. However, it seems that using to the analogy approach can be relevant in specific cases. Indeed, for standard borings (for instance: for the spark plug drills, geometry, tolerance, tools and material are standardized), or other drillings whose process plan is well known to designers, it is useless to generate again these mastered processes.

In order to prevent the PACG from loosing time regenerating the plan of these mastered processes, users can express their know-how with the concept of sequences. In fact, the variant approach, used by experts within the framework of the routine design, is introduced into the PACG by using this concept. These sequences are defined by SABOURIN \& VILLENEUVE [35] as a series of work elements that can be interrupted. It represents the sequencing of the work elements that leads to the realization of a machining feature. In fact, users can express in one cutting tool charts (cf., Section 3.2.4) one mastered process. He has to describe the geometrical features (MEGF) composing the boring to design, the machining parameters and the usual implementations linked. As a consequence, when the PACG algorithm met the geometrical definition of a routine feature, it will not generate all corresponding branches but it will directly load the one saved in a sequence (as illustrated by the annotation 6th in Fig. 9).
In brief, the PACG is a mix of two approaches of planning experts: the generative and the variant methods. Consequently, the more know-how is entered in these sequences, the faster performing will be the algorithm, and thus less useless vertexes will be generated.

\subsubsection{Process scheduling control criteria}

The process scheduling control criterion is one of the algorithms designed to limit the combinatory explosion in the PACG tree. In the design of a process plan, the process planning expert has to select one solution from all appropriate; his choices depend largely on his knowledge and design habits. Like an expert, this algorithm module performs this selection; among the whole machinable features available (considering data contained in the cutting tools charts) it choices only few of them. In this sub-section, methods used to express and formalize the know-how lead by experts to select some solutions are described.

This selection depends on priorities and preferences expressed by the production routing specialist. Principally used when two complex borings are in interactions, these preferences can concern classification of machining operations, definition of key parameters, and so on ... Process planning specialists can express a priority between two machining operations, for example: "I use by order preferably: cycles of pointing, then those of drilling, those of chamfering, operations of boring, and finally tapping". Same criteria can be expressed while exploiting discriminating geometrical parameters (usually the diameter and depth of the axial entities or the surface quality). Enriched by these criteria, the algorithm (Activity 3 in Fig. 8) selects the machining axial features to 


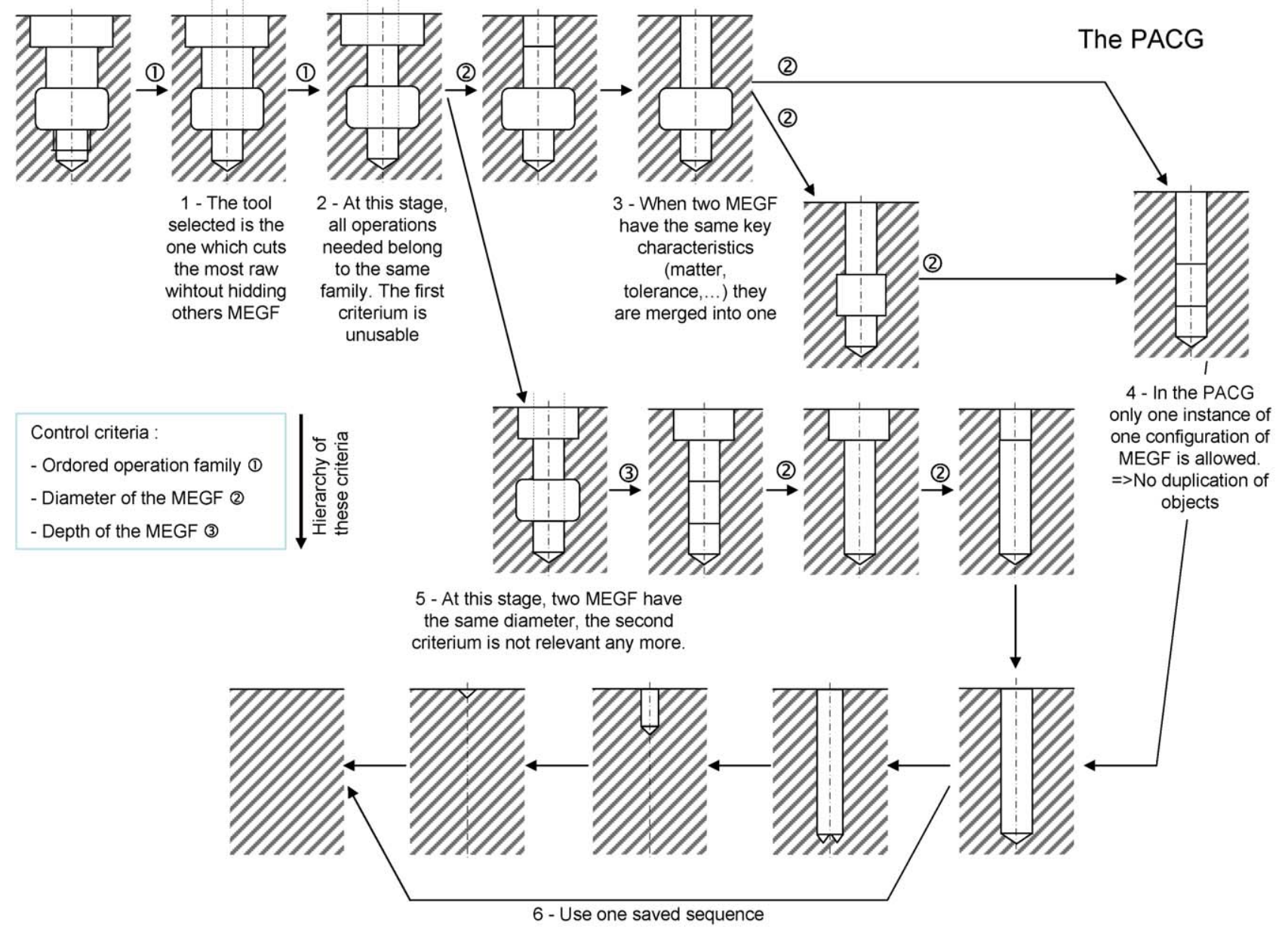

Fig. 9. Example of one PACG tree.

analyze in priority. This strategy will certainly occult a part of possible process plans but it limits the combinative explosion by not generating those local process plans.

There are two methods to realize this control device: expert systems or algorithms. With the first, users can express their criteria with rules (very often used to determine machining and setup parameters $[16,36,37]$, these rules are expressed and coded with the control structure: "If conditions are checked then do something, else do something else"). With only three rules ("Must be realized in first place the finishing operations and after the preform operations", "If two features have the same kind of milling operations, features which have the biggest diameter have to be milled first" and "If several features have the same diameter length, the deepest of them must be machined first") this method based on expert systems can be really efficient. The second way to implement this control system is to use algorithms which manipulate an ordered and hierarchical list of simple criteria. This solution is easy to design and maintain but it needs well formalized rules. These two methods have common deficiencies. The first concerns the consistency of the rules; if the user does not take care of it, the system may diverge or not give any solution since several rules are in contradiction. The second issue is due to the difficulty to precisely formalize production rules and so the resources used by process planning expert to design plans. The fuzzy logic programming which is nowadays employed $[38,39]$ to overcome this uncertainty and ambiguity could be a solution.

In brief, as opposed to common CAPP systems which generate all solutions available for each feature composing one boring (cf.: several new branches start from each feature), the control criterion selects the only one CMEGF which is analyzed to design a stage of the process plan (cf., Fig. 9).

\subsubsection{Cutting tool charts}

The cutting tool charts is a concept defined by VILLENEUVE [13]. In this concept of knowledge formalization and capitalization, the validity range and methods to employ are contained by the solution itself. These charts look like tables where production routing specialists can store the validity domain of a machining process (several machining and geometrical parameters are consigned). This approach is easy to use and deployment seems really natural for users. Combined with the PACG, algorithms can perform plans taking data contained into these charts (and thus the know-how of the corporation) into account.

Thus, for a geometrical feature selected by the previous control (a CMEGF), the algorithm seeks in the cutting tools chart database machining operations and the tools usually used 


\begin{tabular}{|c|c|c|c|c|c|c|}
\hline \multirow[t]{8}{*}{ Rd } & \multicolumn{6}{|c|}{$\begin{array}{l}\text { Note : we wrote the Rd medium value in the lists. } \\
\text { The autorized variation on both sides is } \pm 10 \%\end{array}$} \\
\hline & \multicolumn{6}{|c|}{ Part material : $3 F, 4 F, 4 G$} \\
\hline & \multirow[b]{2}{*}{ Cutting tool } & \multirow[b]{2}{*}{$D t$} & \multicolumn{4}{|c|}{$\min . c t D-\max . c t D$} \\
\hline & & & & $6-8$ & & $10-12$ \\
\hline & $\begin{array}{l}\text { CAST STELLITE } \\
\text { BORING BAR }\end{array}$ & $\begin{array}{l}\text { IT6 } \\
\text { IT7 } \\
\text { IT8 }\end{array}$ & & $\begin{array}{l}0,05 \\
0,05 \\
0,1\end{array}$ & & $\begin{array}{l}0,1 \\
0,1 \\
0,2\end{array}$ \\
\hline & \multirow[b]{2}{*}{ Cutting tool } & & \multicolumn{4}{|c|}{$\min . c t D-\max . c t D$} \\
\hline & & $\mathrm{Dt}$ & $12-20$ & $25-32$ & $40-50$ & $63-80$ \\
\hline & $\begin{array}{l}\text { CARBIDE TIP } \\
\text { BORING BAR }\end{array}$ & $\begin{array}{l}\text { IT6 } \\
\text { IT7 } \\
\text { IT8 } \\
\text { IT9 }\end{array}$ & $\begin{array}{l}0,2 \\
0,2 \\
0,25 \\
0,35\end{array}$ & $\begin{array}{l}0,25 \\
0,3 \\
0,3 \\
0,4\end{array}$ & $\begin{array}{l}0,3 \\
0,4 \\
0,4 \\
0,6\end{array}$ & $\begin{array}{c}\text { nothing } \\
0,45 \\
0,5 \\
0,8\end{array}$ \\
\hline
\end{tabular}

\section{CARTE DE VISITE OPERATIONS}

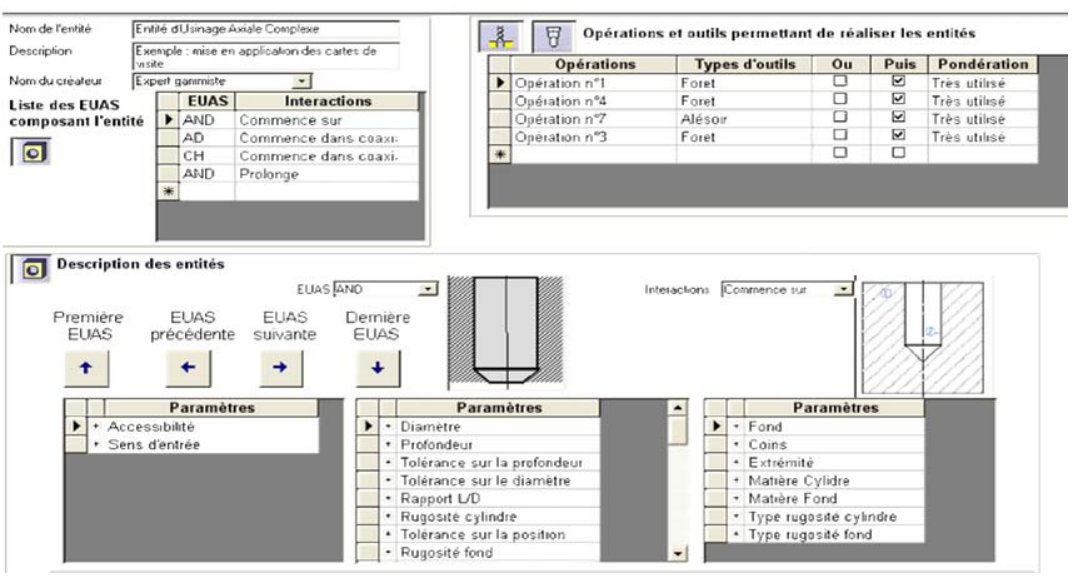

Fig. 10. One tools chart concept example (top) [12] and its under development data base.

by the company (the 2nd Activity described in Fig. 8). If the validity domain of a chart agrees with the geometrical description of the analyzed MEGF, the system instantiates as many Machinable Features as cutting tools charts found. An example of the original cutting tool chart concept [13] is illustrated in Fig. 10. In this figure our realization of this concept with a database is shown too. This software allows users to express their own process rules or tools associations. The modifications are immediately taken into account by the generation system since this database is integrated to the PACG algorithms.

Mainly geometrical parameters and topological interactions are needed on this level: they are enough discriminating for a relevant selection. In short, the generated solutions are restricted to those machinable and known in the user company.

\subsubsection{Machining context}

Another identified deficiency of CAPP systems is the generation of state totally misfit taking technology, physics and the context into account. Indeed as illustrated in Fig. 7, two vertex of the PAG are concerned by this error: the $N_{4}$ and $N_{2}$ nodes. The first boring, even if it stays machinable with a boring bar, is not a relevant solution regarding the context: the machining of its first MEGF hide a part of the other features located under it. The second vertex is worst since three MEGF are totally covered with raw!

That is why another control module is designed to improve the PACG; this one consists in checking the viability of generated geometrical feature regarding the context. This surrounding is mainly composed by the fixture and the axial machining features located in $Z$ - (considering the machining direction). Concretely, the algorithm (realizing the Activity 4 of the chart in Fig. 8) scans all geometrical features located in Zand calculates their accessibility, then if no generated former feature hides those geometrical entities, the machinable feature will be considered as viable and further tests can be performed.

As a result, physically improbable and technologically not very machinable branches are not instantiated in the process planning tree, reducing considerably the number of vertex ...

\subsubsection{Tools selection}

Since a machining feature is the association of geometrical information and machining implementation data, one way to limit combinatorial explosion is to restrain the number of machining features. This goal can be reached by controlling the tool choices of our system.

As a consequence, the last optimization module of the PACG algorithm (Activity 5 in Fig. 8) simply consists in selecting 
relevant tools: instead of instantiate all physically and technologically valid tools, the algorithm will select only those which remove the most raw material considering its intrinsic capabilities (stored in the tools database). With this control, the process planning system no longer suggests for a $150 \mathrm{~mm}$ diameter boring a list of tools composed by milling cutters of less than $10 \mathrm{~mm}$ diameter ...

In the PACG tree the impact of using this control materialises with the reducing of the number of intermediate vertexes (the succession of a dozen stages from a $150 \mathrm{~mm}$ diameter boring to the raw ...) and consequently the number of linking sequences.

\section{Conclusion}

In conclusion, the aim of the study summarized in this paper is the definition of concepts and methods needed to generate machining plans of complex workpieces (made of several borings in interaction) regarding the know-how and capabilities of the company. However, the divergence and the huge number of solutions generated (due to combinatorial explosion) are drawbacks of current systems based on the generative approach.

The first step consists in designing two new features: the MEGF whose goal is to perform the geometrical factoring of the analyzed product, and the Machinable Feature which contains the technical data suitable for the machining of this entity. On the other hand, our participation in this framework is not limited to the definition of new handled entities and their structuring. Indeed, to limit the main issue of current CAPP device: namely the combinatorial explosion, an advanced version of the PAG is designed. Helped by five control algorithms, the PACG is now able to give a dozen result process plans taking the knowledge and capabilities of the user company into account while avoiding divergence.

Our contribution to current studies thanks to the triplet MEGF, machinable features, and machining features is able to perform a precise description of analyzed workpiece without lapsing into the excesses of ordinary methods. Moreover, these new features offer more freedom to users to define their own relevant data. Regarding the PACG algorithms and our improvement choices, our methods can be criticized because these limitations can erase some relevant solutions. Nevertheless, these control algorithms seem to be the only way to reach a compromise between generating innovating solutions complying with the abilities of corporation user and solving too many plans in the frame of features as borings, slots and some specific pockets.

Some concepts and procedures of this method were developed and deployed on the DASSAULT CAD-CAM Software: CATIA. This realization (one test workpiece is given Fig. 11) has validated our geometrical approach, the separation of geometrical and technical information. In short, concepts of Machinable Feature and Machining Enabled Geometrical Features seem reach industrial needs.

However, even if some concepts and methods have been realized and validated by algorithms or other applications, the whole system is needed: indeed only experimentations on several industrial samples would help us to quantify the combinatory explosion issue: this risk exists, but is it finally so awkward? This experimentation, which must incorporate all
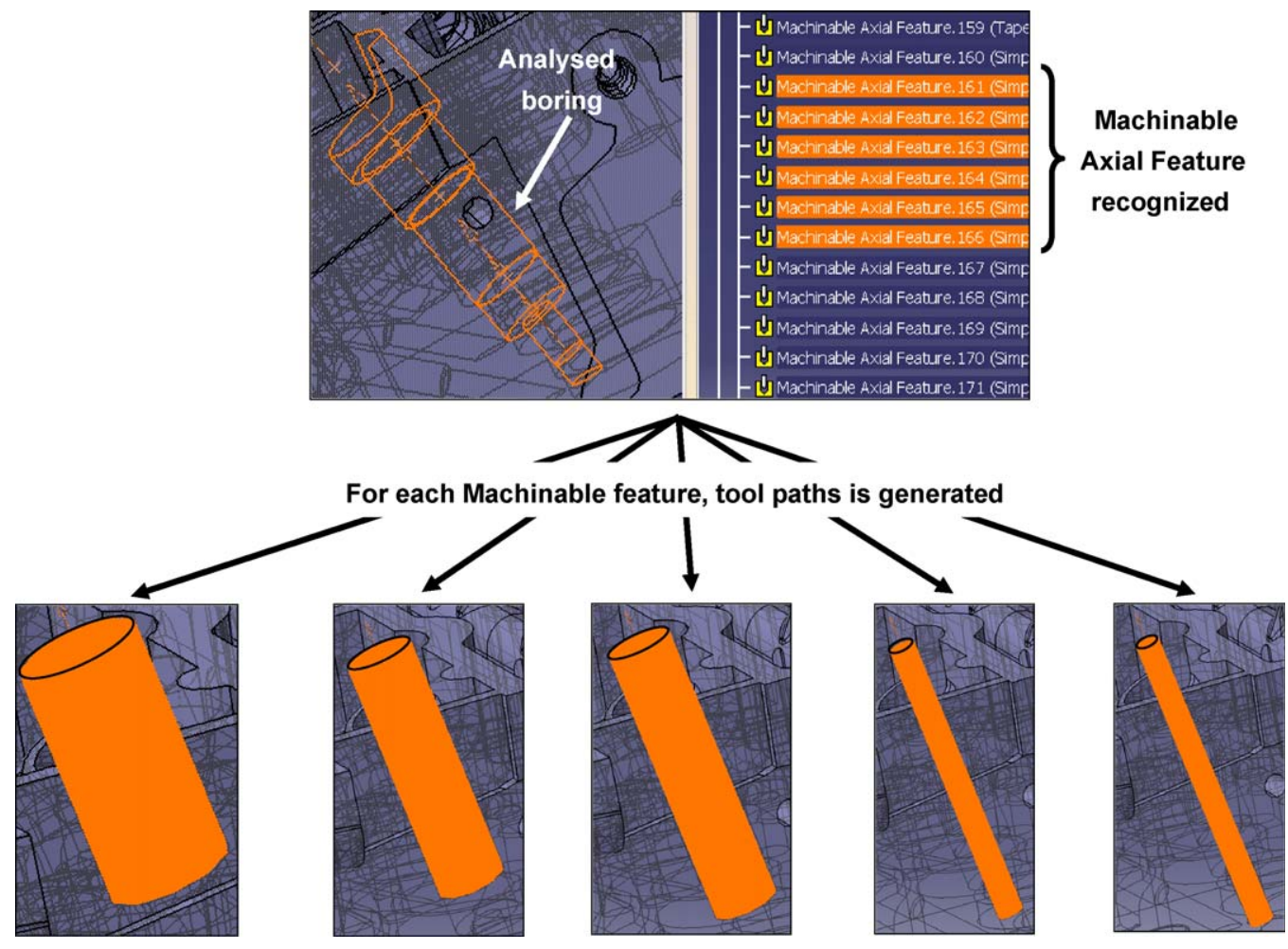

Fig. 11. One part used to validate our method and concepts on DASSAULT CATIA. 
local developments, remains the paramount objective to reach for future work: it will validate all our choices and concrete all data-models.

This study is the starting point of our future works. Actually, this method can be applied to a more general view: instead of analyzing only the geometrical parameters of a complete product, it can be interesting to develop a device able to display in real time the impacts of the designed solution on the manufacturability, the cost and machining time ... This work which occurs within the Design For Manufacturing (DFM) framework will need to formalize all knowledge taking part in the design and manufacturing of a workpiece, the exchanges between these information domains. It will also have to develop advanced tools (a mix of constraints logic programming tools, databases and algorithms) able to lead the designer way of think to foresee the impacts of his choices.

\section{Acknowledgments}

The authors are grateful for funding provided to this project by the French Ministry of Industry, Dassault Aviation, Dassault Systemes, and F. Vernadat for his review and recommendations.

\section{References}

[1] M.E.A. Algeo, S.C. Feng, S.R. Ray, A state of the art survey on product design and process planning integration mechanisms, NISTIR no. 5548, December 1994.

[2] G. Halevi, R. Weil, Principles of Process Planning, Chapman \& Hall, 1992.

[3] A. Vidal, M. Alberti, J. Ciurana, M. Casadesus, A decision support system for optimizing the selection of parameters when planning milling operations, International Journal of Machine Tools and Manufacture 45 (2005) 201-202.

[4] A.K. Kamrani, P. Sferro, J. Handelmann, Critical issues in design and evaluation of computer aided process planning systems, Computers in Industry and Engineering 29 (1-4) (1995) 619-623.

[5] W. Nederbragt, R. Allen, S. Feng, S. Kaing, R. Sriram, Y. Zhang, The NIST Design/Process Planning Integration Project, in: The Proceedings of AI and Manufacturing Research Planning Workshop, Albuquerque, New Mexico, August, (1998), pp. 135-139.

[6] F.J.A.M. Van Houten, A.H. Van't Erve, F.J.C.M. Jonkers, H.J.J. Kals, Part, a CAPP System With a Flexible Architecture, in: Proceeding of the First International CIRP Workshop on CAPP, University of Hanover, 1989.

[7] Z. Huang, D. Yip-Hoï, High-level feature recognition using feature relationship graph, Computer Aided Design 32 (2002) 562-582.

[8] T.C. Chang, Expert Process Planning for Manufacturing, AddisonWesley, USA, 1990, ISBN: 0-201-18297-1.

[9] A. Bernard (sous la direction) Groupe GAMA, Fabrication Assistée par Ordinateur, Hermès, ISBN 2-7462-0618-8, Paris, 2003.

[10] D. Brissaud, Système de génération automatique de gammes d'usinage pour les industries manufacturières, Ph.D. Thesis, University J. Fourrier, Grenoble I, 1992.

[11] H.A. Elmaraghy, W.H. Elmaraghy, A System for modelling geometric tolerances for mechanical design, in: Proceeding of the Third CIRP seminars on Computer Aided Tolerancing, Cachan, France, (1993), pp. $11-24$.

[12] S.G. Park, Knowledge capturing methodology in process planning, Computer-Aided Design 35 (October (12)) (2003) 1109-1117.

[13] F. Villeneuve, M.A.R.C. Barrabes, Object Data Base, AI and CAD-CAM: Application to the process Ascending Generation (PAG) concept, Computers in Design, Manufacturing and Production, in: Seventh Annual
European Computer Conference (IEEE), Compeuro 93, France, LURPA, May, (1993), pp. 320-329.

[14] Y.J. Tseng, A modular modelling approach by integrating feature recognition and feature based design, Computers in Industry 39 (1999) 113-125.

[15] J.J. Shah, M. Mantilla, D.S. Nau, Advances in Feature Based Manufacturing, Elsevier Science, 1994.

[16] J.J. Cunningham, J.R. Dixon, Designing with Features: the Origin of Features, in: Proceedings of the ASME Symposium on Computers in Engineering, CIE, San Francisco, CA, July, (1988), pp. 237-243.

[17] J.J. Shah, P. Sreevalsan, M. Rogers, R. Billo, A. Matthew, Current status of features technology, Technical Report R-88-GM-04.4, CAM-I Inc., Arlington, TX, 1988.

[18] M.J. Pratt, Solid modeling and the interface between design and manufacture, IEEE Computer Graphics and Applications (July) (1984) 52-59.

[19] I.D. Carpenter, P.G. Maropoulos, A flexible tool selection decision support system for milling operations, Journal of Materials Processing Technology 107 (2000) 143-152.

[20] K. Case, M.S. Hounsell, Feature Modelling: a validation methodology and its evaluation, Materials Processing Technology 107 (2000) 15-23.

[21] X.G. Ming, K.L. Mak, J.Q. Yan, A PDES/STEP-based information model for computer-aided process planning, Robotics and Computer-Integrated Manufacturing 4 (1998) 347-361.

[22] F. Giacometti, T.C. Chang, Object-Oriented Design for Modeling Parts, Assemblies and Tolerances, Proceedings Technology of Object Oriented Languages and Systems (TOOLS) (1990) 243-255.

[23] M. Tollenaere (Sous la direction de), Conception de produits mécaniques, Hermès, ISBN 2-86601-694-7, Paris, 1998.

[24] Sabourin L., L'expertise en conception de gammes d'usinage: approche par entités et propagation de contraintes, Ph.D. Thesis, ENS de Cachan, juin 1995. pp. 11-134.

[25] A. Chep, L. Tricarico, P. Bourdet, L. Galantucci, Design of object-oriented database for the definition of machining operation sequences, Computers and Industry Engineering 34 (2) (1998) 257-279.

[26] R.P. Backer, P.G. Maropoulos, An architecture for the vertical integration of tooling considerations from design to process planning, Robotics and Computer Integrated Manufacturing 16 (2000) 122-123.

[27] W.C. Regli, M.J. Pratt, What are feature interactions? in: The 1996 ASME Design Engineering Technical Conference and Computers in Engineering Conference, DFM-1285, Irvine, California, August, (1996), pp. 18-22.

[28] F. Cay, C. Chassapis, An IT view on perspectives of computer aided process planning research, Computers in Industry 34 (1997) 307-337.

[29] T.N. Wong, K.W. Wong, A feature-based design system for computeraided process planning, Journal of Materials Processing Technology 52 (1995) 122-132.

[30] J.X. Gao, Y.S. Tang, R. Sharma, A feature model editor and process planning system for sheet metal products, Journal of Materials Processing Technology 107 (2000) 88-95.

[31] H. Lau, B. Jiang, A generic integrated system from CAD to CAPP: a neutral file-cum-GT approach, Computer Integrated Manufacturing Systems 11 (1-2) (1998) 67-75.

[32] J. Mei, H.C. Zhang, W.J.B. Oldham, A neural network approach for datum selection in computer-aided process planning, Computers in Industry 27 (1995) 53-64.

[33] B. Jiang, H. Lau, F.T.S. Chan, H. Jiang, An automatic process planning system for the quick manufacturing process plans directly from CAD drawings, Journal of Materials Processing Technology 87 (1999) 97-106.

[34] F.L. Zhao, S.K. Tso, P.S.Y. Wu, A cooperative agent modelling approach for process planning, Computers in Industry 41 (2000) 83-97.

[35] L. Sabourin, F. Villeneuve, OMEGA an expert CAPP system, Advances in Engineering Software 25 (1996) 59.

[36] M.R. Alam, K.S. Lee, M. Rahman, Y.F. Zhang, Automated process planning for the manufacture of sliders, Computers in Industry 43 (2000) 254-257.

[37] C. Chung, Q. Peng, The selection of tools and machines on web-based manufacturing environments, International Journal of Machine Tools and Manufacture 44 (2004) 321-322.

[38] C. Derras, Formalisation de l'imprécision informationnelle et des incertitudes décisionnelles des connaissances expertes pour la génération de 
processus de fabrication, Doctorat de l'Université Henri Poincaré Nancy 1, 11 décembre 1998

[39] M.L. Liu, N.V. Sahinidis, Process planning in a fuzzy environment, European Journal of Operational Research 100 (1997) 142-169.

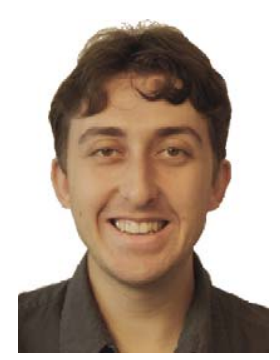

Alain Etienne received his mechanical engineer degree from the ENSAM (Ecole Nationale Supérieure d'Arts et Métiers) in France in 2003. He started in 2004 his $\mathrm{PhD}$ thesis focused in the key characteristics concept and the impact of their variations on the product. He usually works in the fields of computer science, mathematics, tolerancing and constraint based systems. Furthermore, he is involved in several education projects for engineer students.

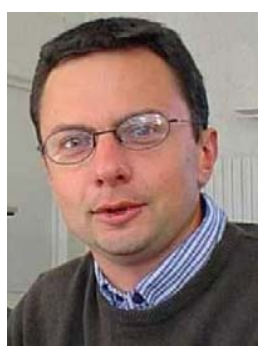

Jean-Yves Dantan is an associate professor in the Laboratory of Industrial Engineering and Mechanical Production at ENSAM (Higher-Engineering Institute for Mechanical and Manufacturing Engineering) at Metz. He obtained his PhD from Bordeaux University in 2000. His research interests include Design for Manufacturing, Tolerancing and CAPP.

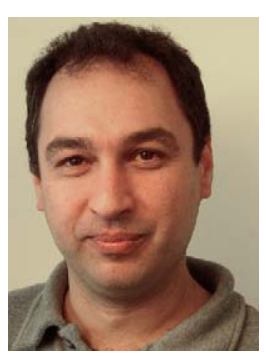

Ali Siadat is an associate professor of computer and industrial engineering in the Laboratory of Industrial Engineering and Mechanical Production at Ecole Nationale Supérieure d'Arts et Métiers, France. He received his $\mathrm{PhD}$ in robotics from Institute National Polytechnique de Lorraine, France in 1998. His research interests include artificial intelligence, information system and knowledge formalization applied to design and manufacturing system.

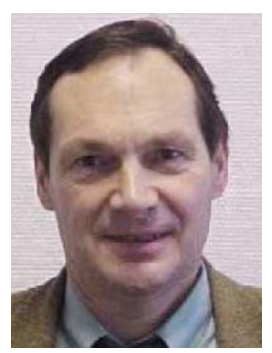

Patrick Martin is a professor in the Laboratory of Industrial Engineering and Mechanical Production at ENSAM (Ecole Nationale Supérieure des Arts et Métiers) at Metz. He is manager of Manufacturing Engineering Laboratory ENSAM, Metz and co-manager of the master degree "High Technological Industrial Products" Cooperation ENSAM-Georgia-Tech. His research interests include Integrated design and manufacturing in production engineering for high quality workpieces, Computer aided process planning, Interaction workpiece-tool-machine in machining and grinding and design and control of manufacturing systems. 